\title{
CROSS-COUNTRY DIFFERENCES IN STOCK MARKET DEVELOPMENT: A CULTURAL VIEW
}

\author{
Eelke de Jong and Radislav Semenov*
}

\section{SOM-theme E Financial markets and institutions}

\begin{abstract}
Although during the last decades the importance of stock markets has increased in all OECD countries, the cross-country differences appear to be remarkably stable. In this paper we relate the factors determining cross-country differences in stock market activity to deeply rooted norms and values in the society, which are represented by the position of countries on cultural dimensions. Stock markets are relatively more important in countries where inhabitants accept more uncertainty and regard competition as a good way of interacting. These attitudes are represented by the national scores on the dimensions of Uncertainty Avoidance and Masculinity. Recent research shows that the differences between countries on these cultural dimensions are very enduring, which suggests that, provided no large shocks occur, the differences in importance of the stock market are likely to persist.
\end{abstract}

This version: June 2002

Key words: corporate governance, culture, stock markets.

Jel-codes: A13, E44, G10, N20

* Corresponding author: Eelke de Jong, Department of Economics, University of Nijmegen, P.O. Box 9108, 6500 HK Nijmegen, The Netherlands, email: e.dejong@nsm.kun.nl 


\section{Introduction}

During the last decades the capitalization of stock markets has increased tremendously in almost all OECD countries. For a group of 19 OECD countries the average of stock market capitalization relative to Gross Domestic Product increased from 0.18 in 1976 to 0.61 in 1996 . This is an important development because well functioning stock markets can play a crucial role in an economy (see e.g. Rousseau and Wachtel, 2000). These markets provide investors with a possible exit mechanism and give them the opportunity to transfer surpluses from short-term assets to longterm capital markets, where the funds can be used for investments by firms. Moreover, the existence of stock markets provides important information that improves the efficiency of financial intermediation. Based upon this reasoning some are of the opinion that the character of the financial system of the industrialized countries will converge towards that of the Anglo-Saxon countries, where stock market capitalization is historically high (see, e.g. Schaberg, 1999, esp. pp. 111-113 for some references).

However, although the capitalization of stock markets has increased in all countries concerned, the differences between the countries have increased; the standard deviation of cross-country levels of stock market capitalization increased from 0.21 in 1986 to 0.37 in 1996. Moreover most countries did not change position when ranked according to the level of stock market capitalization (as a percentage of GDP): the correlation between the figures for 1986 and those of 1996 is 0.92 . This suggests that the pattern of cross-country differences in importance of stock markets is very persistent. Another argument against the convergence hypothesis is that one should be cautious against taking for granted that financial development is unidirectional, and that the current generalized consensus in favor of free markets, because of their obvious efficiency, is irreversible (Rajan and Zingales, 2000, p. 47). Stock markets lead to a greater short-term instability, fail to provide insurance to people and firms against large changes - such as long-term economic downturn and decay of entire industries - and hinder the functioning of institutions which provide such insurance (Rajan and Zingales, 2000, p. 19). Political and economic agents may view these as significant disadvantages, which are great enough to outweigh the 
advantages brought by stock market development. Moreover, differences in financial organization between advanced countries have been very persistent over the last century, during which performance first diverged and then converged (Carlin and Mayer, 1999, p. 2). This raises the question of which factors can explain these differences in financial systems, in particular the differences in importance of stock markets.

Essentially three approaches can be distinguished for explaining crosscountry differences in financial systems: the legal approach, the political approach and the cultural view. The legal approach is brought forward by La Porta and his coauthors (La Porta et al., 1997, 1998, 2000). This approach holds that the key precondition for the development of equity markets is the protection of outside investors through the legal system, including both suitable regulatory provisions and the quality of their enforcement (La Porta et al., 1997). If the legal protection is good, the investments in equity will increase. The authors construct indicators of minorityshareholder rights protection and show that stock market development is significantly related to these indicators. La Porta and colleagues further show that countries with a Common Law origin protect investors better and are therefore more friendly to the development of financial markets. It is not quite clear, however, why this is the case. One reason could be that Common Law leaves more room for judges to adapt their decisions to changes in the economy, while in Civil Law countries judges have no flexibility for interpreting the law. Many researchers, however, argue that this is too weak an explanation (Berglöf and Von Thadden, 1999; Roe, 2000). Berglöf and Von Thadden point out that another interpretation is possible. The correlation between legal origin and financing arrangements may merely reflect the influence of a third exogenous variable. As candidates they suggest the role of the state or the nature of the political system.

The political approach is found in Pagano and Volpin (1999) and Rajan and Zingales (2000). The latter claims that political structures explain the cross-country differences in stock market developments. Rajan and Zingales argue that shifts in political coalitions determine shifts in the character of financial development. In particular, they argue that markets and the resulting competition do not respect the 
value of incumbency and can destroy some forms of insurance provided by social and economic institutions. When political groups especially affected by this become strong, the political system might suppress the development of markets. Disadvantages of their study are that they do not explain systematically why this suppression differs so much across countries and that they use different arguments for explaining developments in different countries: political and cultural factors for the USA and economic arguments for the UK. Pagano and Volpin (1999) model the interaction between entrepreneurs, rentiers, and workers when these three groups have to agree upon the degree of investor protection and the employers' freedom to fire worker. They show that depending on the strength of the workers' preference for working with the same employer, this political process leads to a low level or a high level of protection of investors. The two corresponding equilibria are labeled the corporatist and the noncorporatist equilibrium, respectively. An advantage of that paper is that it relates the extent of investor protection to other aspects of the economy, in particular the employers' freedom to fire employees. It does not, however, explain why one country ends in the corporatist equilibrium and the other in the noncorporatist one. Cultural characteristics could help in this respect.

The cultural approach argues that cross-country differences can be explained by differences between national cultures, defined as systems of beliefs that shape individuals' actions. Studies belonging to this group are Licht et al. (2001), Stulz and Williamson (2001) and Semenov (2000). The study of Stulz and Williamson has an exploratory character. It investigates whether there exists a relationship between characteristics of governance systems and cultural dimensions. It does not provide a preliminary theoretical analysis that would suggest through which mechanisms and in which direction such a relationship is expected. In that study culture is approximated by the dominant religion and the dominant language in a country. These variables are dichotomous. This can be too rough. For example, in the Netherlands the number of Roman-Catholics does not differ much from the number of protestants, so that including the Netherlands in any of the two categories has a highly arbitrary character. Finally, Stulz and Williamson find evidence for a relation between religion and language and creditor rights but cannot find such a relationship for shareholder 
rights. Can this finding be explained substantively or is it due to an incomplete representation of culture? Hence, although we share the view of Stulz and Williamson that culture shapes economic behavior, we suggest that the empirically analyzed relations between cultural and economic variables should be derived by means of a theoretical investigation and that in the empirical analysis a continuous scale is preferred to a dichotomous one. Licht et al. (2001) use cultural variables which are of continuous scale. However, as Stulz and Williamson (2001) they restrict themselves to the correlation between cultural dimensions and indices of regulation and enforcement of regulation. The hypotheses are derived intuitively and are not based on any theory of the functioning of financial markets.

In this paper we present an analysis that remedies the two main disadvantages of previous studies. On the basis of existing theoretical and empirical literature we theoretically derive the factors most relevant for the development of stock markets, and formulate hypotheses about the relation between these factors and cultural characteristics. Thereafter, in the empirical tests we use cultural variables which are measured on a continuous scale. This analysis has the advantage that the empirically observed relationships of cultural and economic variables may be given a clear interpretation. Moreover, in contrast to the previous studies we analyze all relevant factors influencing stock market development, rather than a subset of them such as some regulation issues.

The setup of the paper is as follows. The next section contains a framework for explaining cross-country differences in financial systems and describes relevant characteristics and mechanisms. In Section 3 hypotheses are formulated on the relationship between these mechanisms and the cultural dimensions found by Hofstede (1980). These hypotheses are tested empirically for 19 OECD countries in Section 4. Section 5 deals with the stability of the cultural variables, compares our procedure with the other approaches to explaining cross-country differences in financial systems, and discusses the perspective of this study on the convergence of financial systems. Concluding remarks are presented in Section 6. 


\section{Explaining differences in national financial systems}

\subsection{A framework}

Central in this paper is the idea that culture, economic institutions, economic organization and economic performance are interrelated. By culture we understand "shared cognition, values, norms, and expressive symbols" (DiMaggio, 1994, p. 25). This "collective programming of mind... distinguishes the members of one human group from another" (Hofstede, 1980, p. 21). Following North, we define institutions as "the rules of the game in society or, more formally,... the humanly devised constraints that shape human interaction. In consequence they structure incentives in human exchange, whether political, social, or economic" (North, 1990, p.3). Institutions constitute a framework within which human interaction takes place. They can be divided in formal institutions, such as written rules and legislation, and informal institutions: unwritten codes of conduct that underlie and supplement formal rules. The economic organization is the complex process by which agents interact with each other. The distinction between institutions and organizations is comparable to that between the rules of the game and the game as it is played by the players.

Although we are aware of the fact that there is a two-way causation between culture, institutions, organizations and economic performance, in this paper we focus on the impact of culture on the other factors. Culture influences the preferences of economic agents. These preferences shape the behavior of the agents and hence the organization and the actual performance of an economy. Cultural differences across countries therefore will lead to differences between nations with respect to preferences, economic institutions and organizations. The mental models of investors and managers of firms influence their choices of the mechanisms of their transactions. The aggregate of these choices results in a configuration of financial system. The attractiveness of different mechanisms will depend on the regulatory environment, which in turn will be influenced by the preferences of political agents.

Hence, in order to understand how culture influences stock market development, we have to find out which preferences are relevant for this process, and how these preferences are influenced by cultural norms. We can thus ascertain

whether particular combinations of cultural characteristics are more conductive to the 
development of stock markets. We do not investigate all factors influencing stock market performance but concentrate on those which are relevant for explaining differences in their size across countries.

The capitalization of the stock market is determined as the equilibrium of demand and supply of equity. The demand curve will be determined by the amount of capital available for investments and the attractiveness of investing in shares in comparison to investing in other financial instruments such as bonds, deposits, and property. The supply curve is determined by the attractiveness of issuing shares for managers/owners. Cross-country differences with respect to the attractiveness of shares as investments or as financing instruments are determined by cross-country differences in preferences of investors respectively managers/owners and in the regulatory environment.

\subsection{The demand for shares}

\subsubsection{The volume of money available}

The amount of private money available for investment depends on the financial endowments of the population. This endowment is determined by the size of the country and the prosperity of its inhabitants. Since no data are available about the financial wealth of countries, in the empirical analysis we will use GDP as a scaling variable for correcting for cross-country differences in size and GDP per capita for approximating the wealth per capita.

Capital invested in shares comes from individual and institutional investors. In countries where the institutional investors are less developed less capital will be available for purchase of shares. Therefore, for a given supply the price investors will be prepared to pay will be lower. In particular, if the state plays a significant role in provision of pensions, this will hinder the development of pension funds which are major institutional investors. ${ }^{1}$ The factors relevant for cross-country difference in the state's role in the provision of pensions is discussed in section 2.4.2.

1 A study by Röell (1996) finds a statistically significant (at the 5\% level) negative relationship between the proportion of GDP devoted to public pensions and the size of the stock market. This indicates that the state's greater involvement in the provision of pensions may be crowding out private pension funds and consequently reduces the supply of risk-bearing money. 


\subsubsection{The attractiveness of investments in equity}

Given the amount of capital available for investments, the decision to invest in shares will depend on the attractiveness for the investors of shares compared to other investment opportunities, such as bonds, deposits and property. We follow the literature in assuming that the utility of investors is determined by the return and risk characteristics of the investment. We assume that people are uncertainty averse, that is they tend to prefer the choices (lotteries, investments, etc.) about the risks of which they know more to those about the risks of which they know less. This assumption is validated by empirical evidence and has recently been incorporated in the theoretical literature (see e.g. Bewley, 1986; Gilboa, 1987; Gilboa and Schmeidler, 1989; Schmeidler, 1989).

Investments in equity are more uncertain than those in alternative assets such as bonds and deposits. The attractiveness of investing in shares compared to the other assets will thus depend on the attitude of investors towards uncertainty. More uncertainty averse investors will be prepared to pay less for a share of a given firm. Investors in different countries may differ in the degree of their uncertainty aversion.

Regulatory environment will also significantly influence the attractiveness of investing in shares.

Since the fluctuations in share prices are high, investors want to know the direction in which these prices are likely to move. In order to be able to make such an assessment, they need information on the prospects of the firm. Regular reports on the performance of the firm can provide this information. Moreover investors want to be informed at any moment about important changes in the strategy of the firm. Relatively detailed information about the company's performance is also needed in order to give the investors the possibility to investigate whether the management uses the money provided for the benefit of the firm. When mandatory disclosure rules are more lax, to the extent this influences actual disclosure, the investors will have less information about the firm, and investment in equity will thus be less attractive.

For relatively small investors, the attractiveness of investing in shares will depend on the relative position the investors acquire against corporate insiders 
(managers and large shareholders that have close ties with the management). Shares give the holders the right to vote on the important decisions related to the company, in particular on the membership of the board of directors, to raise the issues to be discussed at a shareholders' meeting, and to start the legal proceedings against directors that breach their duties to shareholders. Without these rights, investors would not be able to extract from corporate insiders the return to their investment. The legislation in different countries, however, may be much more conductive to exercising these rights than in other countries. Furthermore, the corporate insiders are able to obtain important information about the prospects of the firm before any other investor, and can exploit this inside information by buying or selling shares. Regulatory treatment of insider trading may differ across countries. Another disadvantage for small shareholders might be that major investors might trade shares against better terms than are available for small investors. For example, an investor can acquire a majority of the shares and thus control of the firm by offering one or two major shareholders a price that is significantly higher than the current market price, without being forced to buy all shares. The small shareholders are never in the position to earn a higher price than the price listed at the stock market. How the regulations treat such kind of transactions may vary across countries.

Finally, the advantages of buying and holding securities for investors will depend on the level of taxation on the transfer of securities.

Concluding, we expect that demand for shares will be higher in countries where the inhabitants have a lower aversion towards uncertainty, and where the regulatory environment makes investment in shares more attractive.

\subsection{The supply of equity}

The supply curve of shares will be determined by the costs and benefits involved in issuing shares. Issuing public stock incurs significant direct and indirect costs. The direct costs involve the costs of flotation (up to 10 percent of the value of equity) and taxation of security issues. There are also direct opportunity costs related to underpricing of initial public offerings. The indirect costs for managers are the result of the increased necessity to publish the achievements and intentions of the company for the 
future. This increased disclosure bears the risk of informing competitors and might also lead to more pressure for wage increases from employees and pressure to pay dividends (Roëll, 1996).

Notwithstanding these costs there are benefits for managers/owners of going public. Roëll (1996), on the basis of theoretical analysis and a survey of opinions of managers in the USA and some European countries, has identified the following main benefits: cashing in by the initial owner; reducing the level of debt of the firm with proceedings obtained through the public offering; enhanced company image and publicity; benefits resulting for owners/managers from the use of information contained in a share price by (present and future) stakeholders. The first two factors can be consolidated into one: the level of net monetary benefits from issuing shares. This level is the difference of gross benefits and costs. The level of gross benefits, of course, does not influence the supply curve (which indicates how much shares are on offer for any given level of gross benefits). The level of costs, on the other hand, influences this curve. While costs of flotation may differ among countries, we are not aware of any argument that can relate these differences to preferences of agents. The costs of paying taxes on security issues, on the other hand, may systematically differ across countries and will be influenced by preferences of politicians. We are not aware of theoretical arguments or empirical evidence attesting that the importance of publicity differs across countries. ${ }^{2}$ Such differences are likely to exist, however, in level of the benefits resulting for owners/managers from the use of information contained in a share price by (present and future) stakeholders.

2 The type of industry seems to be relevant in this respect. Enhancing public image is more important for firms producing consumer goods than for those producing basic or intermediate products. There is some casual evidence in favour of this proposition. A good example is the difference in attitude between Phillips and AKZO, when both acquired a listing at an American stock market. Phillips, which has an important division in consumer electronics and electric tubes, decided to use the New York Stock Exchange, since this would produce more publicity. In addition the company launched an advertisement campaign entitled "A New Light on the Blue Board", which referred to the electric tubes it sells. At the same time AKZO, a producer of chemical products that are sold to other factories, decided to acquire a listing at NASDAQ. The costs of acquiring a listing were lower than for a listing at NYSE and the Board did not regard the additional publicity associated with a listing at NYSE as of any importance. 


\subsubsection{The importance of information derived from share price}

Future (equity and non-equity) investors will use the equity price as a source of information about the company's value. This information reduces their uncertainty about the company and thus reduces the price for which they are willing to provide capital. Potential and actual employees will judge by the share price whether their job is secure, suppliers - how safe it is to provide the firm with trade credit, and customers - with what probability and for how long the product will be supported (by honouring warranties, providing spare parts etc.).

The importance for a stakeholder of the share price as a source of information depends on how close the relationship with the firm is. When it is close, the stakeholder has less necessity to obtain additional information about the firm from its share prices. This reduces the benefits of issuing shares for owners/managers.

The attractiveness of each of these relationships will be determined by the preferences of the managers. From a thorough investigation of twelve large American corporation Donaldson (1984) derives four motives by which top managers are driven: the desire for self-fulfillment (according to some specific measures of personal and organizational achievement), the desire for independence (of constituencies having control over scarce resources) ${ }^{3}$, the desire for self-sufficiency of the firm, and the desire for survival, that is, for "long-term health and vitality of the organization as an effective and influential corporate presence, with the incumbent managers fully in charge" (p. 21). These motives induce a sustainable growth of the firm as an overarching objective of the top managers. The first three motives are probably quite general for managers across the world. However, Donaldson emphasizes that the desire for self-sufficiency is largely determined by the perception of the American financial environment by managers. In a different environment this motive might be much less strong. Based on this analysis, we assume that managers pursue two objectives: the objective of independence ${ }^{4}$ and the objective of sustained

3 This motive is also suggested, albeit for firms rather than for top managers, by resource dependence theories originating from the work of Pfeffer and Salancik (1978). In particular, this motive produces a preference of internal over external sources of finance; this concurs with 'pecking order' theory of finance (Myers and Majluf, 1984).

4 The objective of self-fulfillment, although important, is less relevant for our purposes 
survival and growth, which can be divided into two subgoals - growth of the firm and reduction of uncertainties. The relative importance of these objectives may differ among societies.

What will determine whether the relationship between a firm and a stakeholder is arm's-length or close? Consider the relationship of a firm with a creditor (a financial institution or a trade creditor). To achieve the same level of utility the creditor would require larger return and/or larger collateral in arm's-length than in close relationships, since in the latter case close knowledge of the firms and greater possibilities of monitoring partially substitutes collateral and other contractual provisions as a devise of disciplining managers and reducing uncertainty for investors. This difference in the return and/or collateral required by the creditor will be larger the more uncertainty averse the creditor is. Thus, the more uncertainty averse the creditor is, the more likely is the goal of sustained survival to be achieved under close relationship. Furthermore, for a manager close relationships with stakeholders involve a greater reduction in independence but also a greater reduction in uncertainty (debt or terms of trade of a contract are easier to renegotiate; bank or trade credit at future dates is more readily available). The managers for whom independence is relatively more important will thus be less inclined to enter in close relationships, and the managers for whom reduction in uncertainty is relatively more important will be more inclined to enter such relationships.

To conclude, the supply curve of equity may systematically differ across countries because of differences in taxation of security issues, and in importance of share price as a source of information for stakeholders (which, in turn, is related to differences in importance of certainty and independence for managers, and in importance of certainty for stakeholders).

\subsection{The role of politicians}

In the previous subsection we have seen that the regulatory environment of the financial system crucially influences the costs and benefits of issuing and buying shares. Moreover, the amount of capital available for investments depends on the

than the other objectives. 
extent the pensions are provided by the government. Both the regulation and the way the provisions of pensions are organized are determined by the decisions of politicians, who are representing the preferences of the population. In this section we relate the characteristics of the regulation and the provision of pensions to the preferences of the politicians.

Following the public choice literature, we assume that politicians care about the prospects of their re-election. They thus seek to introduce policies that will find support in the majority of population. Theoretical and empirical work suggests that the level of well-being and the level of certainty about it are of crucial importance to individuals' welfare: people care about their income and are uncertainty- and riskaverse. Politicians who would like to increase their prospects of re-election would then take measures in favour of a system which promotes economic efficiency and which is less apt to bring about and/or aggravate economic instabilities and fluctuations. ${ }^{5}$ In addition, normative considerations are used for evaluating outcomes and characteristics of economic organizations.

\subsubsection{Regulation}

As we discussed above, politicians will evaluate financial systems on the basis of economic efficiency, certainty of income and stability, and normative considerations. Among those, in regard to financial system the attitude towards concentration of economic power is especially important, as revealed by the studies on the history of financial systems, especially that of the United States of America (see Roe, 1991, 1994). Financial and economic (and thus usually political) power may be more or less acceptable for political agents (and a society as a whole), regardless of its effects on economic efficiency. For example, it may be held that concentration contradicts the principle of equality of opportunity when it increases barriers to entry, or that it contradicts democratic values when it gives powerful agents undue political influence.

5 See e.g. the discussion by Allen (1996) of the criteria on which financial systems should be judged and the description of the history of the financial system in the United States by Rajan and Zingales (2000) in particular pp. 31 and 32. See also Quinn and Wooley (2001) for the evidence that voters punish incumbent political parties when volatility of growth increases. 
Hence, financial systems will be evaluated on the basis of economic efficiency, certainty of income, stability, and concentration of power and wealth. People in all societies are likely to attach some value to these considerations. However, in many cases there will be a trade-off among them, at least in the perception of political agents. Thus, there is often a trade-off between efficiency and stability (Black, 1987; Altman, 1995; Quinn and Wooley, 2001). It is here where cultural differences among societies may play a role.

The extent to which equity markets should be allowed (or encouraged) to develop is a part of a bigger issue: the degree of competition that should exist in the financial system. Equity (and bond) markets provide firms with a source of external finance alternative to financial intermediaries, and thus increases competition in the financial system. Competition goes with an individualistic ethic which is skeptical about a concentration of power and hence favors a small government (see e.g. CPB, 1997, Chapter 5).

In societies with active stock markets the certainty of people's consumption is lower. First, there is a considerable evidence that stock prices are very volatile, more volatile than changes in fundamentals can account for (e.g. Campbell and Shiller, 1988; West, 1988; Leroy and Parke, 1992). This can cause considerable volatility in the consumption of investors who liquidate stocks to finance their consumption (Laffont, 1985). Second, most researchers and practitioners agree that equity markets are quite prone to instability (Crockett, 1996). ${ }^{6}$ This increases the uncertainty of consumption. Third, the fact that firms can be taken over for reasons that have little to do with their performance, and the employees laid off, increases this uncertainty. Fourth, most of the risks individuals face about their lifetime well-being are not insured. Examples are risks of changes in the value of real estate, of changes in the level of national, regional, or occupational incomes, and of changes in the value of one's human capital. There are big practical obstacles for such insurance that make it unfeasible (Allen and Gale, 2000). Intermediaries can ensure individuals against some of such risks, in particular the risk of the change in future values of consumption due

6 Short-term memory of investors, 'herd behaviour', delayed reactions to macroeconomic changes, and some technical features of equity markets are the principal 
to economy-wide shocks (such as oil crises in the early 1970s). However, investors thus have to be prevented from access to equity markets to sustain such a scheme (Allen and Gale, 1995).

Increased competition in the financial system thus increases the uncertainty in consumption. Several authors argue that private credit-creating institutions have an intrinsic predisposition to undergo periodic waves of crisis and bankruptcy. The collapse in the condition of these institutions is then transmitted to all spheres of the economy, producing a general decline. This tendency is exacerbated by competition in the banking sector, since competition induces taking excessive risks (Allen and Gale, 2000) and intensifies 'herd behavior' (see Crockett, 1996). As mentioned earlier, many major risks faced by individuals cannot be insured on the market. Many of them, however, can be and have been insured by communities and through relationships. Increased competition can is destructive for such forms of insurance, without creating new ones ${ }^{7}$ (Polanyi, 1944; Rajan and Zingales, 2000).

The effect of stock markets on economic efficiency is an unsettled issue in the literature. ${ }^{8}$ What is important for our analysis is that there is no overwhelming

reasons for this.

7 For instance, competition makes it harder for long-term bank-firm relationships to form, and increases the risks of firms being shut off from credit in the downturn (Mayer, 1988; Petersen and Rajan, 1995; Rajan and Zingales, 2000).

8 Developed stock markets provide investors with better opportunities to diversify risks, and thus lower risk premia charged for funding new projects. Developed stock markets facilitate investment in high-risk, high-return projects (Morck and Nakamura, 1999; Weinstein and Yafeh, 1998). These positive effects of stock markets are beyond dispute, but most others are not. Some authors suggest that liquid stock markets increase the incentives to invest in long-term projects (Levine, 1991, Bencivenga e.a., 1995) while other argue that liquid markets create a myopic investment climate (Stein, 1988; Bhide, 1993). It has been argued that stock markets quickly disseminate information and aggregate the investors' valuations of firms' performance, which greatly facilitates the efficiency of investment decisions, and that developed stock markets facilitate disciplining of managers, by allowing to link managerial compensation to stock price performance (e.g. Paul, 1992; Holmstrom and Tirole, 1993) and facilitating the operation of the market for corporate control (e.g. Jensen, 1992). However, if stock price at any given moment does not accurately reflect the value of the firm for shareholders, investment decisions based on it may be suboptimal, linking managerial compensation to stock prices may lead to suboptimal decisions, and hostile takeovers based on such price will decrease rather than increase efficiency Shleifer and Vishny, 1988; Shleifer and Summers, 1988; Winter, 1990; Milgrom and Roberts, 1992). The evidence indicates that 
evidence of very large positive effects of the development of stock markets on efficiency, which would have induced people to always prefer more development of stock markets, despite the negative effects on certainty. A similar conclusion can be drawn with respect to the impact of competition on efficiency. On the one hand it has been argued that competition ensures that costs are minimized and the prices of banking services are such that resources are allocated efficiently (Rhoades, 1982; Gilbert, 1984; Frexias and Rochet, 1997). Increased competition can, however, have a negative impact on efficiency, by preventing economies of scale to be realized, by hindering investment in new technologies (to the extent monopoly power is conductive to them), by giving lower-quality borrowers more opportunities to obtain loans, by intensifying moral hazard problems in the relationship between lenders and borrowers, and by facilitating excessive risk-taking (Allen and Gale, 2000). Finally, it is possible that some degree of co-ordination of financial flows by the state can in some circumstances facilitate economic development. The state can achieve such coordination through selected financial intermediaries; competition among intermediaries or from securities markets would make such co-ordination difficult if not impossible.

This discussion suggests that politicians in societies that put a greater emphasis on stability and certainty are more likely to adopt regulatory provisions hampering the development of stock markets, both because stock markets lead to greater instability and uncertainty on their own right and because they facilitate competition in the financial system, which further increases instability and uncertainty for people.

This discussion also suggests that, even given the preferences regarding uncertainty and stability, the overall effect on social welfare (or on the prospects of

the market does not aggregate all public and private knowledge (e.g. Seyhun, 1986; Malkiel, 1992), and, at least in relatively short run, even public information (as evidenced in 'stock market anomalies'; see e.g. Scherer, 1988; Shefrin and Statman, 1995; De Bondt and Thaler, 1995; Allen and Gale, 2000). Furthermore, it has been shown that equity markets may not have advantages over intermediaries in aggregating information (Allen and Gale, 2000). Developed stock markets reduce the effectiveness of another disciplining devise - shareholder monitoring (Shleifer and Vishny, 1986; Bhide, 1993). Finally, to the extent the equity markets are unstable, this may have a negative effect on economic efficiency Crockett, 1996). 
political stability and re-election) of a particular type and level of deliberate coordination in the financial system is extremely difficult to evaluate. In such a situation political agents are likely to put a greater emphasize on those theoretical explanations which correspond to their basic values and beliefs, which are largely shaped by societal norms. Thus, in some countries most influential political agents may believe that the best outcome is achieved by a system with as little deliberate coordination as possible, while in other countries the best outcome may be believed to be produced by a system which involves a significant degree of deliberate coordination.

The belief that financial system should be more competitive will induce regulatory measures aimed at improving the conditions of competition. It also may induce regulatory measures that increase the costs of such coordination among financial institutions and between financial institutions and firms.

Finally, the aversion to concentration of economic power will induce stronger protection of minority investors.

\subsubsection{The state's role in the provision of pensions}

Whether pensions are provided by the state depends on the weight societies attach to such values as stability of income, solidarity and avoiding social exclusion, equality, reduction of poverty, and promoting autonomy (see Goodin et al. (1999) and references therein). There are trade-offs between the various criteria, in particular, between solidarity, on the one hand, and efficiency, autonomy, promoting selfreliance and initiative, on the other. Thus, the society should decide on the relative importance of each of these values. This decision is crucially influenced by deeply rooted cultural values and has a crucial impact on the character of social welfare systems, in particular the systems of pension provision (Rimlinger, 1971; Wilensky, 1974; Kluegel and Miyano, 1995; Becker, 1996). Societies that attach a high importance to solidarity and equality are likely to favor a relatively great state involvement in provision of pensions, while societies stressing autonomy and self reliance are expected to prefer individual pensions schemes. ${ }^{9}$ Societies that are more

9 Thus, a strong emphasis on solidarity played a crucial role in establishing solidaristic and universalistic welfare state in Sweden (Davidson, 1989), while emphasis on 
averse to uncertainty are likely to favor provision of pensions by the state, because at least in the short run- it is by far the most secure source of provision of pensions. ${ }^{10}$

\subsection{Other influences}

In the above discussion we did not consider the influence of ownership patterns on stock market development. Stock markets are likely to be less developed in countries with concentrated ownership, for the following reasons. Since a lesser fraction of equity will be traded on the market, the stock price is likely to be more volatile (Pagano, 1989a,b; Allen and Gale, 1994) and to aggregate the information about the firm less effectively, making disciplining of managers through connecting the managerial remuneration to the stock price more difficult (Holmstrom and Tirole, 1993). Shareholders will buy shares of such a firm at a discount compared to shares of a similar firm with a large fraction of equity traded regularly. This reduces the benefits of going public. Causation also may run in the opposite direction, however. It is well known that prices of securities on thinner stock markets are more volatile, more or less regardless of the share of equity of a particular firm which is traded. Thus, in less developed stock markets the liquidity advantage for investors of the dispersed ownership structure will be smaller, and disciplining of managers through connecting the managerial remuneration to the stock price more difficult. Disciplining through monitoring by large shareholders may be superior. Furthermore, in less developed stock markets the probability of a hostile takeover because of mispricing and not of underperformance of the firm is higher. Managers may want to guard against this possibility. For these reasons the firms may choose to have a concentrated ownership. Because it is unclear which direction of causality is predominant, in this study we do not deal with the relevance of the concentration of ownership for the level of development of stock markets.

individual achievement and individual responsibility for providing for living significantly constrain the development of state welfare policies in the USA (Rimlinger, 1971; Wilensky, 1975; Coughlin, 1980; Tropman, 1981).

10 Thus, the proposals for introduction of funded pensions in Germany are "not popular because of the perceived capital market risk. In particular, most workers find the thought of putting a major part of retirement savings on the stock market rather frightening" 
Until now we have implicitly assumed that the size of a stock market is determined by national factors. However, due to the increased liberalization of international capital flows and national financial markets, one can question the validity of this assumption and argue that the size is also or even to a great extent determined by international factors. Although, we agree that in principle this is a valid argument, we think that there are at least two reasons to believe that in practice national factors are dominant. First we investigate the factors determining the attractiveness of using the stock market for financing and investing. Foreign capital will flow from countries with unfavorable conditions for using the stock market to countries, which enhance the use of stock markets. In this sense international capital flows strengthen our arguments. Second, an important empirical fact is the strong bias of portfolio holdings toward domestic securities (Tesar and Werner, 1995). Although structural barriers to international investments have fallen, the observed level of international diversification remains low (Rowland, 1999). Hence, it is likely that the national factors dominate the international ones when determining the size of stock markets.

\subsection{The final scheme}

The discussion in the previous sections highlights different channels by which crosscountry differences in preferences influence institutions and hence the performance of stock markets. Figure 1 provides a summary of these channels. We identify four major factors that can systematically differ across countries and are influenced by preferences: (1) the regulatory environment; (2) the role of the state in provision of pensions; (2) the attractiveness of buying shares, given the regulatory environment, and (4) the attractiveness of issuing shares, in particular the benefits resulting for owners/managers from the use of information contained in a share price by (present and future) stakeholders. We related these factors to agents' preferences. The attitude towards uncertainty and instability appears to be of primary importance: it is relevant for all four channels. A high level of uncertainty aversion is related to a skeptical attitude towards capital markets and to institutions which are not conducive to the

(Börsch-Supan, 2001). 
development of these markets. So in a country where on average the population is relatively uncertainty avoiding, the rights of minority shareholders are not well protected, the state has a large stake in providing pensions, and the relationships between firms and stakeholders are relatively close. Moreover, investors in these countries prefer safer investments. The attitude towards competition and the attitude towards concentration of economic power influence whether the regulatory environment fosters the development of capital markets; the extent of solidarity with the older generation is relevant for the role of the state in the provision of pensions, and the managers' valuation of independence is of importance for the closeness of the relation between management and stakeholders. In the next section we investigate whether and how cultural features of countries influence these preferences.

< insert Figure 1>

\section{Influence of culture}

As indicators of societies' cultural characteristics we use the cultural variables derived by Hofstede (1980) on the basis of a survey of work-related values, which was conducted in 1968-1973 and embraced about 120,000 native employees of IBM's subsidiaries in 40 countries. The questions were designed to identify particular value orientations of people. On the basis of the responses of people in each country, societies were given scores on each question. Hofstede then factor-analyzed these scores. He identified four dimensions on which national cultures differ. A country could be given a score on each of the dimensions on the basis of scores on each of the orientations which reflect this dimension. These national scores range from almost zero to slightly more than 100. Many other studies on work-related values find the same four dimensions (see Chinese Cultural Connection, 1987; Smith et al. 1994; and Smith et al. 1996). ${ }^{11}$ Table 1 gives the scores for the countries considered in this study.

11 One of them (the Chinese Cultural Connection) has identified an additional dimension: Confucian Dynamism. It refers to the extent to which a society exhibits a pragmatic future-oriented 
For each of the four dimensions distinguished by Hofstede we briefly present its main characteristics and relate these to the factors explaining stock market development. In our explanation we often will present the orientations in a dichotomous way to clarify the characteristics associated with the dimensions and the expected relationship with other variables. The dimensions are, however, continua and countries may lie at any point on it.

Femininity-Masculinity deals with the relative emphasis in society on caring for others and quality of life on the one hand, and achievement and success on the other. Feminine societies stress equality and solidarity and feel that the needy should be helped; managers in these societies strive for consensus. Masculine societies stress competition and feel that the strong should be supported; conflicts are resolved by fighting them out; managers make decisions on their own.

From the different attitude towards competition between masculine and feminine countries we conclude that in a masculine society the regulatory environment is more likely to facilitate competition in the financial system. Hence, the protection of shareholders' rights is expected to be more strict in more masculine societies. The inhabitants of feminine countries stress solidarity and equality and are therefore likely to favour a comprehensive system of pension provision by the state. In a masculine society managers are more reluctant to give up independence than managers in a feminine society. Thus close relationships between firms and stakeholders are more likely in a feminine than a masculine society. All three channels in Figure 2 in which the dimensions Femininity/Masculinity plays a role suggest that in more feminine countries the attitude and regulation is less in favor of enhancing financial markets than in more masculine societies.

Uncertainty Avoidance (UA) refers to the extent to which people feel threatened by uncertainty and ambiguity and try to avoid it and/or protect themselves against it. People in societies high on Uncertainty Avoidance perceive uncertainty

or conventional and short-term perspective. The polar societal norms on this dimension are longterm orientation and short-term orientation. This dimension is available for a few countries only and 
Table 1

Scores of countries on Hofstede's cultural dimensions

\begin{tabular}{|c|c|c|c|c|}
\hline & Femininity & $\begin{array}{l}\text { Uncertainty } \\
\text { Avoidance }\end{array}$ & $\begin{array}{l}\text { Power } \\
\text { Distance }\end{array}$ & $\begin{array}{l}\text { Indivi- } \\
\text { dualism }\end{array}$ \\
\hline Australia & 39 & 51 & 36 & 90 \\
\hline Austria & 21 & 70 & 11 & 55 \\
\hline Belgium & 46 & 94 & 65 & 75 \\
\hline Canada & 48 & 48 & 39 & 80 \\
\hline Denmark & 82 & 23 & 18 & 74 \\
\hline Finland & 74 & 59 & 33 & 63 \\
\hline France & 57 & 86 & 68 & 71 \\
\hline Germany & 33 & 65 & 35 & 67 \\
\hline Greece & 65 & 112 & 60 & 57 \\
\hline Italy & 30 & 75 & 50 & 76 \\
\hline Netherlands & 86 & 53 & 38 & 80 \\
\hline New Zealand & 42 & 49 & 22 & 79 \\
\hline Norway & 92 & 50 & 31 & 69 \\
\hline Portugal & 73 & 104 & 63 & 31 \\
\hline Spain & 58 & 86 & 57 & 51 \\
\hline Sweden & 95 & 29 & 31 & 71 \\
\hline Switzerland & 30 & 58 & 34 & 68 \\
\hline United Kingdom & 34 & 35 & 35 & 89 \\
\hline United States & 38 & 46 & 40 & 91 \\
\hline Uncertainty Av. & 0.131 & & & \\
\hline Power Distance & 0.063 & $0.762^{* * *}$ & & \\
\hline Individualism & -0.233 & $-0.638^{* * *}$ & -0.284 & \\
\hline
\end{tabular}

Source: Hofstede (1980). The Femininity score equals one hundred minus the Masculinity score provided by Hofstede.

**** - significant at 1 percent level

inherent in life as a continuous threat that must be fought. ${ }^{12}$ Thus, they are motivated by security more than by achievement for its own sake; in fact achievement is defined in terms of security. People in these societies tend to reduce ambiguity. Conflict and competition are felt undesirable. People in societies with a low Uncertainty

therefore is neglected in this study.

12 Uncertainty Avoidance is not the same as risk avoidance. See Hofstede (2001), p. 148. 
Avoidance accept uncertainty inherent in life much more easily. They are motivated by achievement which is defined in terms of recognition by others (rather than security). Conflict and competition are perceived as natural patterns of conduct, which can be contained on the level of fair play and used constructively.

In high-UA societies investors will ask a higher uncertainty premium, which reduces the price they are prepared to pay for shares. Hence, we expect a direct negative relation between UA and the development of the stock market. The association of low Uncertainty Avoidance with a positive attitude towards competition suggests that there is a negative relation between UA and protection of the rights of small shareholders. Since inhabitants of high-UA countries attach a high value to security, we expect that in these countries the government's role in the provision of pensions will be higher. Entering a close relationship with the counterpart is a way to reduce uncertainty. In a close relationship there are more mechanisms for controlling the behavior of the other party (manager or shareholder). Consequently, there is an "ideological preference for group decisions, consultative management, against competition" (Hofstede, 2001, p. 160). The average duration of employment with the same company is high (ibid, p. 169). In a high-UA society stakeholders will require more collateral and a higher rate of return (respectively, will give less trade credit), or more information and control, in arm's-length than in close relationships. Close relationships will thus be preferable to managers of firms from a financial point of view. Hence, a positive relation between UA and the closeness of the relationship between shareholders and firms can be expected. All this suggests that higher Uncertainty Avoidance directly and indirectly has a negative impact on stock market development.

Power Distance (PD) refers to the extent to which the society accepts that power within its organizations and the society as a whole is distributed unequally. People in societies with a large Power Distance believe that inequality is existential: a majority of people perceives that there should be an order of inequality in which everybody has a rightful place, and such an order provides the best protection for everyone. People are a potential threat to one's power and rarely can be trusted; cooperation is thus difficult to sustain. People in societies with a small Power 
Distance believe that hierarchy in society is an inequality of roles established for convenience. People of different power levels feel less threatened and more prepared to trust others and engage in cooperation with them.

High Power Distance is associated with less aversion to concentration of power. Hence, we expect that the score on Power Distance is negatively correlated with the provisions for protecting minority share holder rights, thereby negatively influencing stock market capitalization (see Figure 2). In societies with a large Power Distance agents are more reluctant to give up independence. They also expect more opportunism from others and thus will be more reluctant to enter long-term relationships. Thus, close relationships between a firm and a stakeholder are less likely than in a society with small Power Distance, suggesting a positive impact of Power Distance on capital market development. Consequently, the values related to this dimension influence stock market development in opposite directions. Given this, we do not formulate nor test any hypothesis with respect to expected influence of the country's position on Power Distance.

Collectivism-Individualism reflects whether people look only after themselves and their immediate family, or belong to in-groups which look after them in exchange for loyalty. People in collectivist societies have a 'We' consciousness; for them collective interests prevail. In individualist societies people have an 'I' consciousness; for them individual interests prevail. Except for Portugal, all countries are quite individualist. We therefore do not consider this dimension in this study. At the same time, the countries differ significantly on the other three dimensions, which therefore are considered in the following analysis. Of these dimensions the correlation between Uncertainty Avoidance and Power Distance is relatively high and positive (bottom of Table 1).

On the basis of this analysis we would expect stock markets to be more developed in societies with lower Uncertainty Avoidance and in societies with higher Masculinity. In addition to testing these two hypotheses, we can explicitly test the relevance of two of the channels through which we expect culture to influence stock market development, namely the protection of small shareholders' rights and the role 
of the state in the provision of pensions. Hence the following five hypotheses can be tested.

Hypothesis 1. The strength of legislative protection of minority shareholder is positively related to the value of stock market capitalization relative to GDP.

Hypothesis 2. The ratio of publicly provided pensions to national income is negatively related to the value of stock market capitalization relative to GDP.

Hypothesis 3. The strength of legislative protection of minority shareholders, measured by the 'antidirector rights' index, is negatively related to the level of Uncertainty Avoidance and negatively related to the level of Femininity.

Hypothesis 4. The ratio of publicly provided pensions to the national income is positively related to the level of Uncertainty Avoidance and positively related to the level of Femininity.

Hypothesis 5. The value of stock market capitalization relative to GDP is negatively related to the level of Uncertainty Avoidance and negatively related to the level of Femininity.

These hypotheses will be tested in the next section for 19 developed Western countries listed in Tables 1 and 2.

\section{Empirical Evidence}

As the dependent variable we use for most countries the average of the stock market capitalization (as a \% of GDP) during the period 1976 - 1995. The data in Table 2 illustrate that the capital market capitalization is relatively high in the Anglo-Saxon countries and Switzerland, whereas it is very low in Austria, Greece and Italy. 
Table 2

Stock market capitalization relative to GDP

\begin{tabular}{llllll} 
United Kingdom & 0.68 & Sweden & 0.32 & Germany & 0.17 \\
Switzerland & 0.64 & Belgium & 0.23 & Norway & 0.15 \\
United States & 0.55 & Denmark & 0.20 & Italy & 0.10 \\
Canada & 0.42 & Finland & 0.18 & Greece & 0.09 \\
New Zealand & 0.40 & Spain & 0.18 & Portugal & 0.07 \\
Australia & 0.39 & France & 0.17 & Austria & 0.06 \\
Netherlands & 0.36 & & & & \\
\hline
\end{tabular}

The values are averages over the period of 1976-1995, except for Finland (1983-1995), New Zealand (1985-1995), Norway (1981-1995), and Portugal (1978-1994).

Source: Calculated from the data in Demirguc-Kunt-Maksimovic database available from the World Bank website.

The results of the regression ${ }^{13}$ testing the relevance of the two intermediate variables for the relative stock market capitalization (Hypotheses 1 and 2) are reported in Table 3. We see that in both cases the relationships are indeed important empirically. ${ }^{14}$ When including both variables in the same regression, the coefficients of the variables are not significant, while the variance explained is higher than in either of the reported regressions. This is an obvious case of multicollinearity, which is to be expected given the correlation of -.58 between the two variables.

13 The results presented result from estimation by means of Ordinary Least Squares. Before estimating the relations we first have investigated whether there are influential observations, which could lead to heteroscedasticity. Since this never appeared to be the case the Ordinary Least Squares estimates are correct.

14 The relationship of the relative stock market capitalization with the 'anti-director right' index was identified for a sample of 45 countries by La Porta et al. (1998). The existence of the relationship of capitalization and the ratio of publicly provided pensions to national income was first mentioned by Roëll (1996) for developed European countries (although she does not report the results of the regression). 
Table 3

Stock market capitalization and some explanatory variables: results of regressions

\begin{tabular}{lcc}
\hline Intercept & $0.130^{* *}$ & $0.622^{* * *}$ \\
& $(2.19)$ & $(5.11)$ \\
'Anti-director' rights index & $7.060^{* * *}$ & \\
& $(3.66)$ & $-3.176^{* * *}$ \\
Ratio of public pensions to & & $(-3.77)$ \\
national income in 1984 & & .26 \\
Adjusted $R^{2}$ & .30 & \\
\hline
\end{tabular}

$t$-statistics in parentheses. The superscripts ${ }^{*},{ }^{* *},{ }^{* * *}$ indicate a significance level of 10 , 5 and 1 percent respectively.

Source: Ratio of publicly provided pensions to the national income in 1984 : OECD (1988). The data on New Zealand and Norway are not available for this variable.

Antidirector rights index: La Porte etc (1998) This variable has a range from 0 to 5 and is formed by adding 1 when: (1) shareholders are allowed cast a vote by mail (rather than attend general meetings personally); (2) shareholders do not have to deposit their shares for several days before and after the general meeting; (3) the minimum percentage of share capital that entitles a shareholder to call an extraordinary shareholders' meeting is less or equal to 10 percent (the median of the sample, which ranges from 1 to 33 percent); (4) cumulative voting for directors allowed; (5) there are legal mechanisms which can be used by minority shareholders against a perceived oppression by directors (e.g., suing directors or the right to force the company to purchase back the shares of shareholders who object to certain fundamental changes).

Since according to Hypotheses 3 trough 5 two types of cultural dimensions are suggested as explanatory variables, a question emerges whether these two factors will interact in their influence. Would differences in Femininity, say, affect these characteristics with the same force in high- and low-UA societies? It might be that the effects of the two dimensions 'cancel out' to some extent. An interaction term (the product of the two variables involved) is added to the regressions in order to test whether this is the case. The model thus has the form $y=\beta_{U 0} U A+\beta_{F 0} F E M+\beta_{U F} U A \cdot F E M+\varepsilon$, where $U A$ and FEM are scores on corresponding dimensions. This implies that the true coefficient of $U A$ obtained from the model is $\beta_{U}=\beta_{U 0}+\beta_{U F} F E M$. The hypothesis that is tested in this case is: 
'Both $\beta_{U 0}$ and $\beta_{U F}$ do not significantly differ from zero'. The appropriate statistic is the $F$-statistic for this joint hypothesis (and not the $t$-statistic for $\beta_{U 0}$ ). The same, of course, is true for FEM. The value of $t$-statistic of $\beta_{U F}$, on the other hand, reflects whether there is indeed an interaction between the influence of the two independent variables.

The results of testing of Hypotheses 3 and 4 are reported in columns 1 and 2 of Table 4. We see that all hypotheses are confirmed. Protection of minority shareholders is weaker in more Uncertainty Avoiding countries. The state plays a larger role in provision of public pensions in countries with a high score on Uncertainty Avoidance and on Femininity. The results of testing Hypothesis 5 are reported in column 3 of Table 4. We see that the hypothesis is confirmed. Stock markets are more developed in countries with lower Uncertainty Avoidance and higher Masculinity. ${ }^{15}$

It is possible that cultural characteristics influence the development of stock markets only through one of the mechanisms we discussed. In this case the analysis of relationships of financial systems with culture may be of limited interest. On the other hand, if controlling for the influence of one mechanism, cultural indicators have a direct link with stock market capitalization, this would indicate that other mechanisms (including those for which no measurable intermediate variables are available) also play an important role, and would underscore the importance of the cultural analysis. The estimations, presented in columns 4 to 6 of Table 4 , indicate that cultural characteristics exercise influence on stock market development also through channels other than, anti-director rights index and the ratio of publicly provided pensions.

15 We also run regressions that include Power Distance as an independent variable. In regressions of antidirector rights index and public pensions, the coefficient of Power Distance is not significant, confirming our expectations that values related to this dimension do not influence these variables. In the regression of stock market capitalization the coefficient of Power Distance is positive and significant at 10 percent level. This result is not robust, however. After excluding the outlier Austria, the coefficient of Power Distance becomes insignificant. The values and significance levels of other coefficients are in all cases similar to those in the regressions not including the Power Distance index. 
Table 4

Antidirector rights index, public pensions provision, relative stock market capitalization and cultural characteristics: results of regressions

\begin{tabular}{|c|c|c|c|c|c|c|}
\hline & \multirow{2}{*}{$\begin{array}{c}\text { Antidirector } \\
\text { rights index } \\
1\end{array}$} & \multirow{2}{*}{$\begin{array}{l}\text { Public } \\
\text { pensions } \\
2\end{array}$} & \multicolumn{4}{|c|}{ Stock market capitalization } \\
\hline & & & 3 & 4 & 5 & 6 \\
\hline Intercept & $8.936^{* * * *}$ & $\begin{array}{l}-12.433^{* *} \\
(-201)\end{array}$ & $\begin{array}{l}1.308^{* * * *} \\
(489)\end{array}$ & $0.596^{*}$ & $1.190^{* * * *}$ & $0.991^{* * * *}$ \\
\hline UA score & $-10.874^{* * *}$ & $0.422^{* * * *}$ & $-1.469^{* * *}$ & $-1.562^{*}$ & $-0.912^{*}$ & $-0.413^{* * *}$ \\
\hline & $(-3.42)$ & $(5.46)$ & $(-3.31)$ & $(-1.94)$ & $(-1.94)$ & $(-3.95)$ \\
\hline FEM score & $-7.69^{* *}$ & $0.307^{* * * *}$ & $-1.199^{* *}$ & $-1.257^{*}$ & $-0.762^{*}$ & $-0.338^{* *}$ \\
\hline & $(-2.61)$ & $(6.84)$ & $(-2.91)$ & $(-2.03)$ & $(-1.77)$ & $(-2.24)$ \\
\hline UA*FEM & $13.226^{* *}$ & $-0.597^{* * *}$ & $1.675^{* *}$ & $1.775^{*}$ & 0.822 & \\
\hline & $(2.43)$ & $(-4.42)$ & $(2.26)$ & $(1.79)$ & $(1.02)$ & \\
\hline $\begin{array}{l}\text { 'Anti-director' } \\
\text { rights index }\end{array}$ & & & & $\begin{array}{l}-0.706 \\
(-0.16)\end{array}$ & & \\
\hline Pensions & & & & & $\begin{array}{l}-1.797 \\
(-1.60)\end{array}$ & $\begin{array}{l}-2.509^{* *} \\
(-2.79)\end{array}$ \\
\hline$F$-stat. UA & 10.28 & 16.76 & 10.25 & 3.55 & 5.38 & \\
\hline [p-value] & {$[0.001]$} & {$[0.0002]$} & {$[0.001]$} & [0.057] & {$[0.018]$} & \\
\hline$F$-stat. FEM & 3.76 & 9.76 & 5.20 & 3.75 & 3.51 & \\
\hline [p-value $]$ & [0.046] & {$[0.002]$} & [0.019] & [0.049] & {$[0.058]$} & \\
\hline Adjusted $R^{2}$ & 0.47 & 0.65 & 0.52 & 0.49 & 0.55 & 0.56 \\
\hline
\end{tabular}

$t$-statistics in parentheses. ' $F$-stat. UA' denotes the $F$-statistic for the test of the hypothesis: 'Both the coefficient of the UA score and of the interaction term UA*FEM do not significantly differ from zero'. ' $F$-stat. FEM' has a similar meaning. For source and definitions of the variables we refer to the notes to Tables 1,2 and 3. 


\section{Discussion}

\subsection{Stability of values}

The argument of this paper is that a causal relation exists from culture to institutions and economic organization to economic performance. There are three generally accepted requirements for establishing a causality: there must be a statistical association between two variables, the cause must temporally precede the effect, and the association between the two variables should not be the result of a 'third' variable. Hofstede's cultural dimensions are based on the results of a survey undertaken in the late 1960s, while our data on stock market capitalization refer to the 1980s and the 1990s. However, historical studies indicate that contemporary differences in stock market development among countries have been formed decades ago (e.g. Rajan and Zingales, 2000). The time order requirement therefore cannot be satisfied in a conventional way. This situation often arises in social research. In such cases the validity of causal relations is evaluated at the basis of relative fixity or alterability of the variables: the suggested cause should be less alterable than the suggested effect (e.g. Punch, 1998). The majority of sociologists agree that populations of nations hold deeply rooted values which change very slowly, only within centuries. The question, however, is whether values identified by Hofstede are such deep-rooted values.

There is considerable evidence that this is indeed the case and that crosscountry differences in values reflected by the dimensions (with a possible exception of Individualism) have not changed significantly in at least the last century and a half, and probably for much longer. Hofstede finds that Power Distance is positively correlated with the size of the country concerned. Power Distance and Masculinity are strongly related to geographical latitude and historical factors. In Europe, for example, countries that long ago comprised the Roman Empire exhibit larger Power Distance. The strong Femininity of Scandinavian countries can be traced to the character of Viking societies when women had to manage the villages when men were away on sea trips.

The differences in the level of Uncertainty Avoidance in developed countries are closely related to the differences in the relationships between the individual, the society, and the state, which have been relatively stable at least in the last century and 
a half. Societies differ in the locus of ultimate authority for collective action (Jepperson, 1999). Collective purpose and authority may be located in a society at large (so the state is considered as an instrument of society and has little independent legitimization) or in a differentiated organizational center, (so "the state represents and arrogates the public realm, while society represents a private sphere subject to state tutelage" (Jepperson, 1999, p. 9)). 16. Jepperson (1999) thoroughly analyzes the dominant political philosophies, ideologies and institutional arrangements of several developed countries. He shows that these have not radically changed in the last century and a half. It is remarkable that that in societies with a higher Uncertainty Avoidance collective purpose is located in the society as a whole, while in societies with higher Uncertainty Avoidance it is located in a differential organized centre. This is quite understandable: social rationality and 'tutelage' relieve individuals from the necessity of making choices in some very uncertain situations and provide insurance against many unforeseen situations, thus reducing uncertainty.

Further evidence is provided by comparative analysis of law. The scholars usually divide the legal systems by their origin (and some other characteristics) into two broad legal traditions: Common Law and Civil Law. The philosophy of Common Law stresses rights rather than duties, emancipation rather than control, responsibility rather than paternalism. Common Law emphases the right of the individual to dispose of himself and his property to the exclusion of every other interest. Civil Law, on the other hand, stresses duty, authority and order. It tends to be paternalistic and often 'protects individuals against themselves' - something that Common Law never does (e.g. Chloros, 1978). The connection of these differences with basic distinguishing characteristics of high-UA and low-UA societies is evident. And, indeed, societies with Common Law score lower on the Uncertainty Avoidance index than societies with Civil Law. The legal systems in question are formed by the beginning of the nineteenth century (and the traditions on which they are based are several centuries older), and their philosophy and fundamental legal provisions did not substantially

16 What is understood by such a centre may differ: it may be the state in the meaning given to it in English, or Staat in the German sense, which refers to the organized political community as a whole. 
change since then. This suggests that the same is very likely to be true for relative levels of Uncertainty Avoidance in societies.

Summarizing, there are several arguments in favor of the proposition that Power Distance, Masculinity and Uncertainty Avoidance are deeply rooted in the Western societies and have been stable in Western countries over at least the last century. This view is confirmed by Hofstede's summary of empirical studies in this field, which concludes that altogether data from 140 studies comparing from 5 to 39 countries were found to be significantly correlated with one or more of the dimensions discussed above (Hofstede, 2001, p. xx).

\subsection{Relationship with other explanations}

Two explanations of the cross-country differences in stock market development have been suggested in the previous literature. In this subsection we discuss how our explanation is related to them.

La Porta e.a. (henceforth LLSV, 1998) argue that when investors are protected from expropriation, they pay more for securities, making it more attractive for entrepreneurs to issue these securities. They find that the differences in the development of stock markets are significantly related to differences in legislative protection of minority shareholders and in quality of enforcement of this legislation.

As mentioned in the Introduction, this approach has received substantial criticisms in the literature. Roe (2000), in particular, argues that legal factors play an important role in explaining differences in financial development between developed and developing countries. But as long as the legislation enforcing basic property and contract rights is in place and is enforced reasonably efficiently, differences in specific measures of legal protection of minority shareholders are unlikely to play a major role, since they can be compensated for by private means.

In the framework of our theory, both views can be accommodated. We allow for the possibility that legal provisions may be an important determinant of the development of capital markets. However, we suggest that these provisions are shaped by more fundamental factors, in particular cultural values. At the same time, 
this is not the only, and perhaps not the major channel through which values influence financial development.

LLSV (1998) also find that the strength of legislative protection of investors and the extent of development of capital markets are related to origins of countries' legal systems. In particular, common law countries provide investors with better legislative protection, enforce these provisions better, and have more developed capital markets than civil law countries. There has been some discussion on why this is the case. LLSV (2000) suggest that political and historical differences between mother countries shape their laws. They argue that in England in the seventeenth century the crown lost control of the courts to parliaments dominated by property owners, and common law evolved to protect the latter against the crown (this protection was later expanded to investors). In France and Germany, on the other hand, parliaments were weaker, commercial codes were adopted only in the nineteenth century, and the state maintained political control over firms and did not surrender its power of economic decisions to courts. In this interpretation, the relationship of indicators of investor rights and financial development with legal origins is found because legal origins correlate with the extent of state intervention in the economy. The differences in the extent of state intervention will be largely determined by cultural differences. Some arguments on how this occurs were made in the previous section. We argue, however, that there are also other mechanisms through which cultural factors influence financial development.

Pagano and Volpin (1999) build a theoretical model at which the political process may lead to either high or low protection of investors. The authors assume that disutility of work decline during the employment relationship, reflecting, in particular, a growing attachment to work place. The process is more likely to result in low investor protection (1) the stronger is the decline of disutility of work as the employment relationship lasts longer; (2) the lower is the propensity of workers to invest in shares rather than in other mediums; and (3) the higher is the propensity of political groups (workers, entrepreneurs, and rentiers) to cooperate in the political process. The authors do not investigate how these factors differ across countries. We have argued in Section 3 that the former two factors will be influenced by cultural 
values related to Uncertainty Avoidance and Masculinity. It can be argued theoretically and shown empirically that the propensity of employers and employees to cooperate in the political process is also related to culture; in particular, it is higher in societies with higher Uncertainty Avoidance, lower Masculinity and lower Power Distance (Semenov, 2000). Our analysis thus suggests a possible explanation of why particular countries arrive at particular outcomes predicted by Pagano and Volpin's model.

It can easily be seen that out of the countries in our sample, the countries of Scandinavian legal origin (Denmark, Finland, Norway, Sweden) differ from the countries of other origins in their low Masculinity scores (the only country with a similar score is the Netherlands). Among the other countries, all countries with English legal origin (Australia, Canada, New Zealand, the UK, the USA) have lower Uncertainty Avoidance scores than other countries, and among the latter all countries with German legal origin (Austria, Germany, Switzerland) have lower Power Distance scores than countries of the French legal origin (Belgium, France, Greece, Italy, Portugal, Spain), except, again, the Netherlands. Only one country - The Netherlands - has to be reclassified to make the correspondence perfect. Countries with similar legal origins have similar scores on some of Hofstede's dimensions, scores that differ from countries of other legal origins ${ }^{17}$.

Rajan and Zingales (2000) note that extent of development of stock markets in various countries changed greatly over time. Before the Great Depression, stock markets in countries such as France and Germany were more developed than in Great Britain or the USA. In most countries, the roots of the Great Depression were seen in excessive investment by industry, excessive credit creation by banks, and excessive speculation on the stock markets. These, in turn, were blamed on the unrestricted competition in the 1920s. Politicians decided to restrain competition and reintroduce stability in the industrial and financial sector. The government also wanted private investments to go through the banking sector rather than through markets because these flows could be more easily directed to preferred activities. In a number of

17 Similarly, a very strong relationship between legal origins and cultural characteristics is observed when we consider the whole LLSV sample; see Semenov (2001). 
countries, measures were put in place restricting the ability of corporations to issue securities in the market, and reducing the attractiveness of certain securities.

The major exceptions were Britain and its colonies and the United States. The authors suggest that a major 'reason for the resilience of financial markets in England was the great importance of trade and cross-border financial flows to its national output, and therefore the greater political power of traders and financiers relative to industrialists. In the United States competition in the financial sector was not restricted because of the inherent decentralization of the system, the checks and balances existing in it. President Roosevelt clearly intended to intervene to restrain the excess volatility in the product and financial markets. The US Supreme Court, however, challenged the constitutionality of many crucial elements of Roosevelt's program. Roosevelt's fight against the Court made many influential figures anxious about growing executive powers, and growing threats to property. This brought about a conservative alliance, which ensured that Congress held up much of the New Deal legislation. The authors mention that 'the instinctive, almost ideological, American fear of centralized power was also instrumental in the growing opposition to Roosevelt's plans' (Rajan and Zingales, 2000, p. 34).

There is little doubt that political factors influence financial systems. Our thesis, however, is that politics is influenced by culture. Cultural variables cannot explain each particular political change. However, they can say something about the direction of such changes. Before World War I and the Great Depression, politicians in most countries believed in the necessity of adhering to the relentless logic of competitive markets for economic success. This belief was stronger than any reservations to such logic that could be contained in culture. As long as the economy developed successfully, this situation persisted. However, this believe was shattered by the Great Depression. The extent to which it was abandoned was determined by cultural values, as were the new beliefs that replaced it. As we have argued, in countries with high Uncertainty Avoidance or high Femininity these beliefs favor a more reserved approach to markets, and in the former group of countries - also an important role of stability in the economy. Cultural differences can thus explain why the stance of politics has changed in the way it has. As we have seen, Rajan and 
Zingales utilize cultural factors (such as fear for centralized power) to account for the developments in the USA.

\subsection{Perspective on convergence}

In this section we investigate the consequences of the results of our study for the discussion on convergence mentioned in the Introduction. In order to do that we first have to be more specific on what is meant by convergence. We speak of convergence if we see a process that leads to more similar levels of stock market capitalization. Indicators for such a process are: through time the standard deviation of figures on national stock market capitalization (as a percentage of GDP) and the strength of the relation between cultural values and stock market capitalization decrease.

Empirical evidence indicates that the standard deviation of national stock market capitalization has increased significantly: from 0.21 in 1986 to 0.37 in 1996. In every country except Canada the difference between its relative stock market capitalization and the sample mean was larger in 1996 than in 1986. In all countries with relative capitalization below the mean in 1986 relative capitalization increased less than the mean increase in the sample, while in virtually all countries with relative stock market capitalization above the mean in 1986 relative capitalization increased more than the mean increase in the sample (the exceptions are Canada, New Zealand and Sweden). There is thus little empirical evidence that the relative size of stock markets is converging. The relative positions of countries also do not change much. As mentioned in the Introduction, the correlation coefficient between the values of relative stock market capitalization in 1986 and 1996 is 0.92 .

This suggests that the influence of cultural differences on differences in stock market has not decreased over this period. This can be tested more rigorously by conducting regressions where the independent variable is the stock market capitalization in 1986 and 1996. These results (not shown) are qualitatively similar to the ones we report in Table 4, columns 3 through 6 . The statistical significance of the coefficients in the regressions of capitalization in 1986 and 1996 is very similar; the values of all coefficients increase from 1986 to 1996 by a value very similar to the ratio of standard deviations in the dependent variables in the two years (about 1.5). 
The variance explained, however, decreases slightly (from 0.58 to 0.52 ), indicating that the role of other factors than cultural differences may have increased somewhat in some countries. Overall, cross-country differences in absolute values of relative stock market capitalization in this period have increased with relative positions of most countries remaining similar, and these relative positions continue to be significantly influenced by cultural dimensions. Hence, the results of this paper reaffirm the position of those who argue that economic organizations are embedded in deeper layers of society, which do not change vastly (see Section 5.1). As a consequence, provided no great external shocks occur, the relative importance of the stock market changes only very gradually.

How likely is it that during the next decades external shocks or trends will dominate the influence of cultural variables on the factors determining stock market development? As we saw in the previous subsection, historically other factors played an important role till the 1920-30s. It is in principle possible that the role of these factors, relative to culture, will greatly increase, and to the extent they facilitate convergence, it is possible that the level of development of stock markets will converge.

One may argue that at least three external trends are occurring which might appear to be of importance for the convergence of financial systems, namely: ageing of the population, harmonization of economic legislation within the European Union, and internationalization of product and financial markets. The first two trends are relevant for, respectively, the role of the state in the provision of pensions and the regulatory environment. Internationalization has been argued to lead to a convergence of: (1) values, (2) regulatory environment, and (3) firm-shareholder relationships. It may also alter relative costs and benefits of different forms of financing and mechanisms of corporate governance. In accordance with our scheme that values determine the other factors, we first discuss the possibility that internationalization will lead to a convergence of values. Then follows an investigation of the possible effects of these trends on the four factors found in Section 2: the regulatory environment, the role of the state in providing pensions, the attractiveness of buying shares (given the regulatory environment), and the closeness of the relationship 
between firms and stakeholders. Thereafter the implications of internationalization on the relative costs and benefits of different forms of financing and mechanisms of corporate governance are discussed.

It has been argued that an increase in interaction between people of different cultures and in exposure of people of different nations to the same technologies may lead to a convergence of values. This statement, however, is at variance with research on the attitude of British and French students educated at INSEAD in France, of Eurocrats in Brussels and of employees of multinational companies. The crosscultural interaction reminds the members of various countries of the "differences between one set of cultural views and another, and this seems to lead to a slight intensification of cultural traits" (Hampden-Turner and Trompenaars, 1993, p. 375). Hofstede (2001) confirms this position and provides a wealth of evidence indicating that differences between national cultures reflected in scores on dimensions have not diminished since the end of 1960s and are unlikely to diminish in the future. Hofstede concludes that "there is no reason they should not remain recognizable until at least 2100" (Hofstede, 2001, p. 36).

During the last decade in several OECD countries proposals have been put forward to change the regulation in order to enhance the development of stock markets, to increase the rights of small shareholders and to increase the transparency of the corporate accounts. Often, special committees on the functioning of the financial system made these proposals: the Bradford commission in the UK, the Peters committee in The Netherlands, the Viénot commission in France. There have been some changes in the regulation of some OECD countries that might enhance the development of stock markets. However, the implementation of these recommendations goes very slowly. In some cases new initiatives even seem to counteract the proposals by these committees. In the Netherlands for example, the SER (an advisory board) has proposed to increase the influence of employees on the company's boards, which is expected to hamper the influence of shareholders. At the European level it is even difficult to come to new legislation. After 12 years of preparation the plans for a new directive establishing cross-border takeovers were voted down by the European Parliament on July 4th 2001. It could take up to three 
years before the European Commission can present a new draft to the parliament (The Economist, July 7th 2001). This directive aimed to ensure an adequate level of protection of minority shareholders. At the end of the same month, the rights of these minority shareholders were set at naught in the takeover of Telecom Italia by Pirelli and the Benetton family. "A treatment which will kill the market" (The Economist, August 4th, 2001). Hence, although, there are forces in continental Europe to improve the rights of small shareholders, this process is slow and confronted with many setbacks.

Due to the ageing of the population, the role of governments in providing pensions is expected to decline in countries, where traditionally this role is relatively large, such as many of the continental European countries. In this respect many recommend to rely more on private pensions and funded pension schemes at the expense of the pay-as-you-go schemes. ${ }^{18}$ This development should go hand-in-hand with that of strengthening the financial market infrastructure, including the establishment of a modern and effective regulatory framework (OECD, 2000, p. 8). Some reforms in this direction have been made ${ }^{19}$. However, once again one can observe great (very often emotional) resistance in many countries, which slows down the speed of these reforms.

Given the regulatory environment, the attractiveness of investing in shares is determined by the uncertainty aversion of investors. As we have argued before we do not expect that the cross-country differences in values will change drastically. Consequently we think that this will not contribute to a convergence of the importance of the stock market.

It is difficult to establish with certainty whether there are trends to convergence in relationships of firms with stakeholders. The evolution of investorfirm relationships in the United States and Japan received much attention in the literature and is likely to be indicative of general trends. It is well known that in the

18 This view is also held by those who foresee large transition problems and who are skeptical about the advantages of fully funded systems; see Miles and Timmermann (1999) and Boldrin et al (1999).

19 Information in this respect can been found on the webside of the OECD: www.oecd.org 
1950-70s the Japanese financial system was characterized by close bank-firm relationships and stable shareholdings, while the relationships of firms and investors in the USA were arm's-length. In the 1980s, there were signs that the systems were converging: there was anecdotal evidence that some of the largest Japanese firms weakened their connections with main banks, and that a significant reduction of intragroup shareholdings within the keiretsu was taking place. On the other hand, in the USA some institutional investors began to take an active stance in corporate governance. Many authors have expected a very significant convergence of the systems. However, the evidence suggests that it has not happened. In the 1970-90s Japanese companies increased the share of borrowing from the main bank; the proportion of firms which changed their main bank decreased for medium-size firms; the number of directors dispatched from city banks to other listed companies increased by 34 percent from 1980 to 1993 . Evidence of a survey by OECD shows that corporations do not expect the demise of main bank relationships. Intra-group shareholdings within the keiretsu decreased only slightly and remained significant. Thus, there is little evidence of a decline in the importance of the main bank system, keiretsu system, and the pattern of stable shareholdings (Corbett, 1998). With respect to the United States, observers generally agree that while institutional investors' role in corporate governance has been growing in recent years, only a minority of them exercises such activism. It has not become a significant feature of American system of corporate governance, and in most firms the relationship with all investors remains at arm's-length.

Many authors suggest that internationalization of product markets puts increasing competitive pressures on firms to obtain finance from the least expensive sources and to adopt more efficient mechanisms of corporate governance. If these sources are capital markets, and if these mechanisms are arm's-length relationships with investors and the market for corporate control, the development of both of which is greatly facilitated by a developed stock market, then we may see a development of stock markets in countries where they are thin to levels similar to those where they are advanced. 
Underlying the convergence thesis is the assumption that there is, indeed, a single most efficient mechanism of industrial finance. However, as we argued in Section it is unclear that one system dominates the other. It is well known that any arrangement has both advantages and disadvantages, and different arrangements may be (approximately) equally efficient overall (e.g. Boyer, 1996; Shleifer and Vishny, 1997). More efficient financial arrangements may differ for different industries (e.g. Porter, 1990; Allen, 1993; Soskice, 1996; Mayer, 1998). Thus, the end result may very well be not a convergence of financial systems in different countries but specialization of countries with particular financial systems in industries in which these systems are more efficient.

Even if the best practice would exist, there are significant grounds to doubt that the forces of internationalization are strong enough to induce convergence to it. The share of exports in GDP remains quite small in all countries except some small open economies, and has not increased significantly in the recent decades in most countries. The level of international trade is still lower now in most countries than in 1913 (Wade, 1996). Similarly, all available indicators show that financial markets were more integrated in the late nineteenth and the early twentieth century than ever since (Zevin, 1992). Stock markets, however, remain far from being integrated. Investment continues to be strongly constrained by domestic savings and cannot be very easily financed from other countries' savings (Wade, 1996). The difference in the price of borrowed funds remains substantial, and not very different from several decades ago.

There are significant forces impeding convergence. First, in the opinion of many researchers national production systems are rather tightly bundled packages of specific national resources, institutions and legacies. This 'tightness of fit' makes it extremely unlikely that any one practice or institution can be readily changed without change in other aspects of the system (e.g. Streeck, 1991; Woolcock, 1996; Schmidt and Tyrell, 1997; Hollingsworth, 1997). Second, in all industrial countries processes of economic integration and globalization have generated an upsurge of reaction and resistance in national politics. New political battles have broken out over whether domestic institutions and practices in one's own society ought to be restructured to 
conform to institutions and patterns elsewhere (Berger, 1996). Third, and more generally, any change in governance mechanisms is connected with costs of transition of various kinds, which economic and political agents may be unwilling to accept.

We may conclude that some convergence does occur in two of the mechanisms we have identified as mediating the influence of culture on stock market development: the character of the regulatory environment and the role of the state in the provision of pensions, and that these mechanisms in all countries increasingly take the form more similar to that in countries with more developed stock markets. In both cases, however, this process is connected with many setbacks and is not as farreaching as many have expected. Differences in the other mechanisms are unlikely to diminish significantly without powerful external shocks. We thus expect that while the levels of development of stock markets in different countries may converge somewhat, significant differences among countries are likely to persist in the future.

\section{Conclusion}

In this paper we have related the cross-country differences of stock market capitalization in OECD countries to national culture, where culture is the shared norms and values in a society. By means of a theoretical investigation we have derived the hypothesis that stock market capitalization is relatively high in countries that score low on the index of Uncertainty Avoidance and high on the index of Masculinity, two cultural dimensions found by Hofstede. Empirical evidence confirms this hypothesis. This result reaffirms the position of those who argue that economic organizations are embedded in deeper layers of the society. As a consequence, provided no great external shocks occur, the cross-country differences in importance of the stock market changes only gradually.

\section{Acknowledgement}

We gratefully acknowledge comments on a previous version of this paper by Harry Garretsen and an anonymous referee, and on research incorporated in this paper by Pieter Ruys. 


\section{References}

Allen F., 1993, Stock Markets and Resource Allocation, in C. Mayer and X. Vives, eds., Capital Markets and Financial Intermediation, Cambridge, Cambridge University Press, p. 81--108.

Allen F., 1996, The Future of the Japanese Financial System, Wharton Financial Institutions Center, Working Paper.

Allen F and D. Gale, 1997, Financial Markets, Intermediaries, and Intertemporal Smoothing, Journal of Political economy, 105, 523-46.

Allen F and D. Gale, 2000, Comparing Financial Systems, Cambridge, MIT Press.

Altman M., 1995, Business Cycle Volatility and Economic Growth: The Historical Record, 1870-1986, Journal of Post Keynesian Economics, 17, 561-77.

Becker U., 1996, Over de Typologie van Welvaartsbestellen: EspingAndersens Theorie in Discussie, Beleid and Maatschappij, 23, 1, p.19-30.

Bencivenga V.R., B.D. Smith and R.M. Starr, 1995, Transaction Costs, Technological Choice and Endogenous Growth, Journal of Economic Theory, 67, 53177.

Berglöf E. and L. von Thadden, 1999, The Changing Corporate Governance Paradigm: Implications for Transition and Developing Countries, conference paper, annual World Bank conference on development economics.

Berger S., 1996, National Diversity and Global Capitalism: Introduction, in Berger S. and R. Dore, eds., National Diversity and Global Capitalism, Ithaca, Cornell University Press.

Bewley T. F., 1986, Knightian Decision Theory: Part 1, Yale Cowles Foundation, Discussion Paper 807.

Bhide A., 1993, The Hidden Costs of Stock Market Liquidity, Journal of Financial Economics, 34, 1-51.

Black F., 1987, Business Cycles and Equilibrium, Oxford, Basil Blackwell.

Boldrin, M., J.J. Dolado, J.F. Jimeno and F. Peracchi, 1999, Rescuing unfunded pensions: Suitably amended, unfunded schemes remain a good idea, Economic Policy 29, 289-320. 
Boot A.W.A., S.J. Greenbaum and A.V. Thakor, 1993, Reputation and Discretion in Financial Contracting, American Economic Review, 83, 1165-83.

Boot A. and A. Thakor, 1993, Self-Interested Bank Regulation, American Economic Review, 83, 206-12.

Börsch-Supan A.H., 2001, The German Retirement Insurance System, in A.H. Börsch-Supan and M. Miegel, eds., Pension Reform in Six Countries: What Can We Learn from Each Other?, Berlin, Springer, p. 13-38.

Boyer R., 1996, The Convergence Hypothesis Revisited: Globalization but Still the Century of Nations?, in Berger and Dore (1996).

Campbell J. and R. Shiller, 1988, Stock Prices, Earnings, and Expected Dividends, Journal of Finance, 43, 661-76.

Carlin W. and C. Mayer, 1999, Finance, Investment, and Growth, mimeo

Chinese Cultural Connection, 1987. Chinese Values and the Search for Cultural-free Dimensions of Culture, Journal of Cross-Cultural Psychology, 18(2), 143-164.

Chloros A.C., 1978, Common Law, Civil Law and Socialist Law: Three Leading Systems of the World, Three Kinds of Legal Thought, Cambrian Law Review, 9, 11--26.

Corbett J., 1998, Changing Corporate Governance in Japan, in M. Balling, E. Hennessy and R. O'Brien, eds., Corporate Governance, Financial Markets and Global Convergence, Dordrecht, Kluwer.

Coughlin, 1980 Ideology, Public Opinion, and Welfare Policy: Attitudes Toward Taxes and Spending in Industrialized Societies, Berkeley, University of California.

CPB; Netherlands Bureau for Economic Policy Analysis, Challenging Neighbours: Rethinking German and Dutch economic institutions, Berlin, Springer Verlag.

Crockett A., 1996, The theory and practice of financial stability, De Economist, 144 (1996) nr.4 p.531-568. 
Davidson A., 1989, Two Models of Welfare: The Origins and Development of the Welfare State in Sweden and New Zealand, 1888-1988, Stockholm, Almqvist\&Wiksell.

De Bondt W.F.M. and R.H. Thaler, 1995, Financial Decision-Making in Markets and Firms: A Behavioral Perspective, in R. Jarrow, V. Macsimovic, and W.T. Ziemba, eds., Finance, Amsterdam, Elsevier.

DiMaggio P., 1994, Culture and Economy, in N.J. Smelser and R. Swedberg, eds., The Handbook of Economic Sociology, Princeton, Princeton University Press.

Donaldson G., 1984, Managing Corporate Wealth, New York, Praeger Publishers.

Frexias X. and J. Rochet, 1997, Microeconomics of Banking, Cambridge, MIT Press.

Gilbert R., 1984, Bank Market Structure and Competition: A Survey, Journal of Money, Credit and Banking, 16, 617-44.

Gilboa I., 1987, Expected Utility Theory with Purely Subjective NonAdditive Probabilities, Journal of Mathematical Economics, 16, 65-88.

Gilboa I. and D. Schmeidler, 1989, Maxmin Expected Utility with a Non-Unique Prior, Journal of Mathematical Economics, 18, 141-53.

Goodin R. e.a., 1999, The Real Worlds of Welfare Capitalism, Cambridge, Cambridge University Press.

Hampden-Turner, C. and F. Trompenaars, 1993, The Seven Cultures of Capitalism: Value systems for creating wealth in the United States, Britain, Japan, Germany, France, Sweden, and The Netherlands, London, Piatkus.

Hofstede G., 1980, Culture's Consequences, Beverly Hills, Sage.

Hofstede G., 2001, Culture's Consequences, Beverly Hills, Sage, second edition.

Hollinggsworth J.R., 1997, Continuities and Changes in Social Systems of Production: The Cases of Japan, Germany, and the United States, in J.R. Hollingsworth and R. Boyer, eds. Contemporary Capitalism: The Embeddedness of Institutions, Cambridge, Cambridge University Press.

Holmstrom B. and J. Tirole, 1993, Market Liquidity and Performance 
Monitoring, Journal of Political Economy, 101, 678-709.

Ibbotson, R.G. and J.R. Ritter, 1995, Initial public offerings, In: R.A. Jarrow, V. Maksimovic and W.T. Ziemba, eds., Handbook of Finance, Amsterdam, North Holland

Jensen M.C., 1992, Market for Corporate Control, in P. Newman, M. Milgate and J. Eatwell, eds., The New Palgrave Dictionary of Money and Finance, New York, Macmillan.

Jepperson R., 1999, Institutional Logics: Two Fundamental Dimensions of Structuration Distinguishing Variants of the Modern Nation-State, Stanford University, mimeo.

Kluegel J.R. and M. Miyano, 1995, Justice Beliefs and Support for the Welfare State in Advance Capitalism, in J.R. Kluegel, D.S. Mason and B. Wegener, eds, Social Justice and Political Change: Public Opinion in Capitalist and PostCommunist States, Berlin, Walter de Gruyter.

La Porta R., F. Lopez-De-Silanes, A. Shleifer and R.W. Vishny, 1997, Legal Determinants of External Finance, Journal of Finance, 52, 1131--50.

La Porta R., F. Lopez-De-Silanes, A. Shleifer and R.W. Vishny, 1998, Law and Finance, Journal of Political Economy, 106, 1113--1155.

La Porta R., F. Lopez-De-Silanes, A. Shleifer and R.W. Vishny, 2000, Investor Protection and Corporate Governance, Journal of Financial Economics, 58, $3-27$.

Laffont J.-J., 1985, On the Welfare Analysis of Rational Expectations Equilibria with Asymmetric Information, Econometrica, 53, 1-29.

Leroy S. and W. Parke, 1992, Stock Price Volatility: Tests Based on the Geometric Random Walk, American Economic Review, 82, 981-92.

Levine R., 1991, Stock Market, Growth, and Tax Policy, 46, Journal of Finance, 1445-65.

Licht, A.N, C. Goldsmith and S.H. Schwartz, 2001, Culture, Law, and Finance: Cultural Dimensions of Corporate Governance, mimeo

Malkiel B.G., 1992, Efficient Market Hypothesis, in P. Newman, M. Milgate and J. Eatwell, eds., The New Palgrave Dictionary of Money and Finance, New York, 
Macmillan.

Mayer C., 1988, New Issues in Corporate Finance, European Economic Review, 32, 1167--89.

Mayer C., 1998, Financial Systems and Corporate Governance: A Review of the International Evidence, Journal of Institutional and Theoretical Economics, 154, 44--165.

Miles, D. and A. Timmermann, 1999, Risk sharing and transition costs in the reform of pensions systems in Europe, Economic Policy, 29, 253-286.

Morck R. and M. Nakamura, 1999, Banks and Corporate Control in Japan, Journal of Finance, 54, 319-40.

Myers S. and N. Majluf, 1984, Corporate Finance and Investment Decisions When Firms Have Information that Investors Do Not Have, Journal of Financial Economics, 13, 187- 221.

North D., 1990, Institutions, Institutional Change and Economic Performance, New York, Norton.

OECD, 1988, Reforming Public Pensions, Paris, OECD.

OECD, 2000, Reforms for an Ageing Society, Paris, OECD.

Okun A.M., 1975, Equality and Efficiency: The Big Tradeoff, Washington, The Brookings Institution.

Pagano M. and P.F. Volpin, 1999, The Political Economy of Corporate Governance, University of Salerno, Working Paper.

Paul J.M., 1992, On the Efficiency of Stock-Based Compensation, Review of Financial Studies, 5, 471-502.

Petersen M.A. and R.G. Rajan, 1995, The Effect of Credit Market Competition on Lending Relationships, Quarterly Journal of Economics, 110, 40744.

Pfeffer J. and G.R. Salancik, 1978, The External Control of Organizations: A Resource Dependence Perspective, New York, Harper \& Row.

Polanyi K., 1944, The Great Transformation, New York, Rinehart.

Porter M., 1990, The Competitive Advantage of Nations, London, Macmillan. 
Punch, K.F., 1998, Introduction to Social Research: Quantitative and Qualitative Approaches, Sage, London.

Quinn D.P. and J.T.Wooley, 2001, Democracy and National Economic Performance: The Preference for Stability, American Political Science Review, 45, 1138-51.

Rajan R.G. and L. Zingales, 2000, The Great Reversals: The Politics of financial Development in the 20th century, Working Paper, University of Chicago.

Ramey G. and V.A. Ramey, Cross-Country Evidence on the Link between Volatility and Growth, American Economic Review, 85, 1138-51.

Rhoades S, 1982, Welfare Loss, Redistribution Effects and Restriction of Output due to Monopoly in Banking, Journal of Monetary Economics, 9, 375-87.

Rimlinger G.V., 1971, Welfare Policy and Industrialization in Europe, America, and Russia, New York, Wiley.

Roe M.J., 1991, A Political Theory of American Corporate Finance, Columbia Law Review, 91, 10--69.

Roe M.J., 1994, Strong Managers, Weak Owners: The Political Roots of American Corporate Finance, Princeton, Princeton University Press.

Roe M., 2000, The Quality of Corporate Law Argument and its Limits, Columbia Law and Economics Working Paper.

Röell A., 1996, The Decision to Go Public: An Overview, European Economic Review, 40, 1071--81.

Rousseau P.L. and P. Watchel, 2000, Equity Markets and Growth: Cross-

Country Evidence on Timing and Outcomes, 1980-1995, Journal of Banking and Finance, 24, 1933-1957.

Rowland, P.F., 1999, Transaction Costs and International Portfolio Diversification, Journal of International Economics 49, 145-170.

Schaberg, M., 1999, Globalization and the Erosion of National Financial Systems: Is Declining Autonomy Inevitable?, Chetenham UK, Edward Elgar.

Scherer F.M., 1988, Corporate Takeovers: The Efficiency Agument, Journal of Economic Perspectives, 2, 1, 69--82.

Schmeidler D., 1989, Subjective Probability and Expected Utility without 
Addititvity, Econometrica, 57, 571-87.

Schmidt R.H. and M. Tyrell, 1997, Financial Systems, Corporate Finance and Corporate Governance, European Financial Management, 3, 333--361

Semenov R., 2000, Cross-Country Differences in Economic Governance: Culture as a Major Explanatory Factor, Ph.D. thesis, Tilburg University.

Semenov R., 2001, Culture, Law and Finance, mimeo, University of Nijmegen.

Seyhun H.N., 1986, Insiders' Profits, Costs of Trading, and Market Efficiency, Journal of Financial Economics, 16, 189--212.

Shefrin H. and M. Statman, 1994, Behavioral Asset Pricing Theory, Journal of Financial and Quantitative Analysis, 29, 323-47.

Shleifer A. and R.W. Vishny, 1986, Large Shareholders and Corporate Control, Journal of Political Economy, 94, 461--488.

Shleifer A. and R.W. Vishny, 1988, Value Maximization and the Acquisition Process, Journal of Economic Perspectives, 2, 1, 7--20.

Shleifer A. and R.W. Vishny, 1997, A Survey of Corporate Governance, Journal of Finance, 52, 737--783.

Smith, P.B., Peterson, M.F. Akande, D., Callan V., Cho, N.G., 1994, Organizational Event Management in 14 Countries: A Comparison with Hofstede's Dimensions. In: A.M. Bouvy, F.J.R. van de Vijver, P. Boski and P. Schmitz, eds., Journeys into Cross-Cultural Psychology, Amsterdam, Swets and Zeitlinger, 364-73.

Smith, P.B., Dugan, S. and Trompenaars F., 1996. National Cultural Values of Organizational Employees: A Dimension Analysis Across 43 Nations, Journal of Cross-Cultural Psychology, 27, 231-64.

Soskice D., 1996, German Technology Policy, Innovation, and National Institutional Framework, discussion paper, Social Science Research Center, Berlin.

Stein J.C., 1988, Takeover Threats and Managerial Myopia, Journal of Political Economy, 96, 61--80.

Stiglitz J.E., 1985, Credit Markets and the Control of Capital, Journal of Money, Credit and Banking, 17, 133-52.

Streeck W., 1991, Productive Constraints: On the Institutional Conditions of 
Diversified Quality Production, in E. Matzner and W. Streeck, eds., Beyond Keynesianism: The Socio-Economics of Production and Employment, London, Edward Elgar.

Stulz R.M. and R. Williamson, 2001, Culture, Openness, and Finance, NBER working paper.

Tesar L.L. and I.M. Werner, 1995 Home Bias and High Turnover, Journal of International Money and Finance 14(4), 467-492.

Tropman J.E., 1981, The Constant Crises: Social Welfare and American Cultural Structure?, in J.E. Tropman, M.J. Dluhy, and R. M. Lind, eds, New Strategic Perspectives on Social Policy, New York, Pergamon Press.

Wade R., 1996, Globalization and Its Limits: Reports of the Death of the National Economy Are Greatly Exaggerated, in Berger S. and R. Dore, eds., National Diversity and Global Capitalism, Ithaca, Cornell University Press.

Weinstein D.E. and Y. Yafeh, 1998, On the Costs of a Bank-Centered Financial System: Evidence from the Changing Main BankRelations in Japan, Journal of Finance, 53, 635--72.

West K., 1988, Bubbles, Fads and Stock Price Volatility Tests: A Partial View, Journal of Finance, 43, 639-56.

Wilensky H.L., 1974, The Welfare State and Equality: Structural and Ideological Roots of Public Expenditures, Berkeley, University of California Press.

Woolcock S., 1996, Competition among Forms of Corporate Governance in the European Community: The Case of Britain, in Berger S. and R. Dore, eds., National Diversity and Global Capitalism, Ithaca, Cornell University Press.

Zevin R., 1992, Are World Financial Markets More Open? If So, Why and with What Effects?, in T. Banuri and J.R. Schor, eds., Financial Openness and National Autonomy: Opportunities and Constraints, Oxford, Oxford University Press. 
This document is created using PDFmail (Copyright RTE Software)

http://www.pdfmail.com

Figure 1 The determinants of stock market development

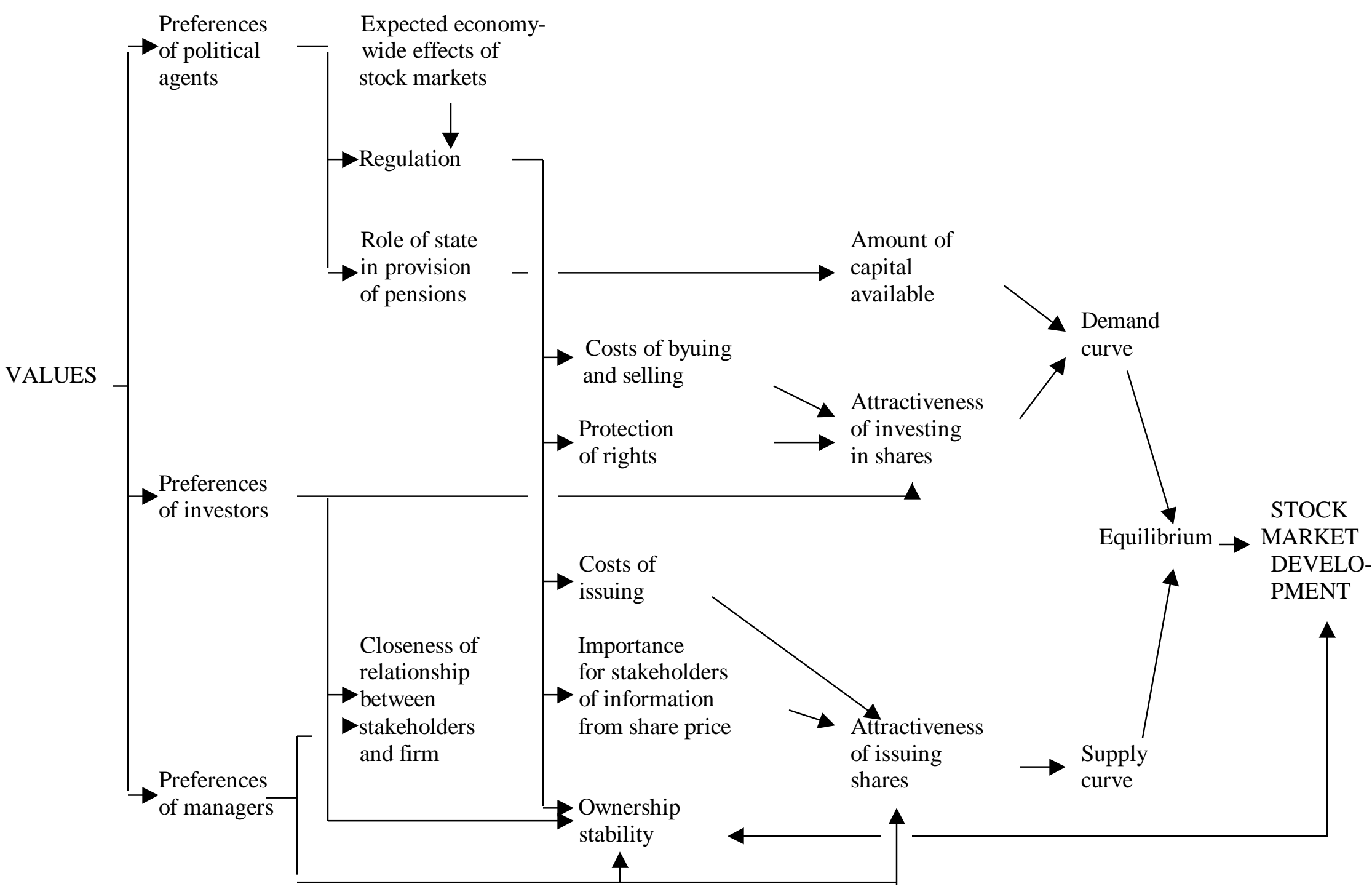


This document is created using PDFmail (Copyright RTE Software)

http://www.pdfmail.com

Figure 2 The hypotheses with respect to the determinants of stock market development

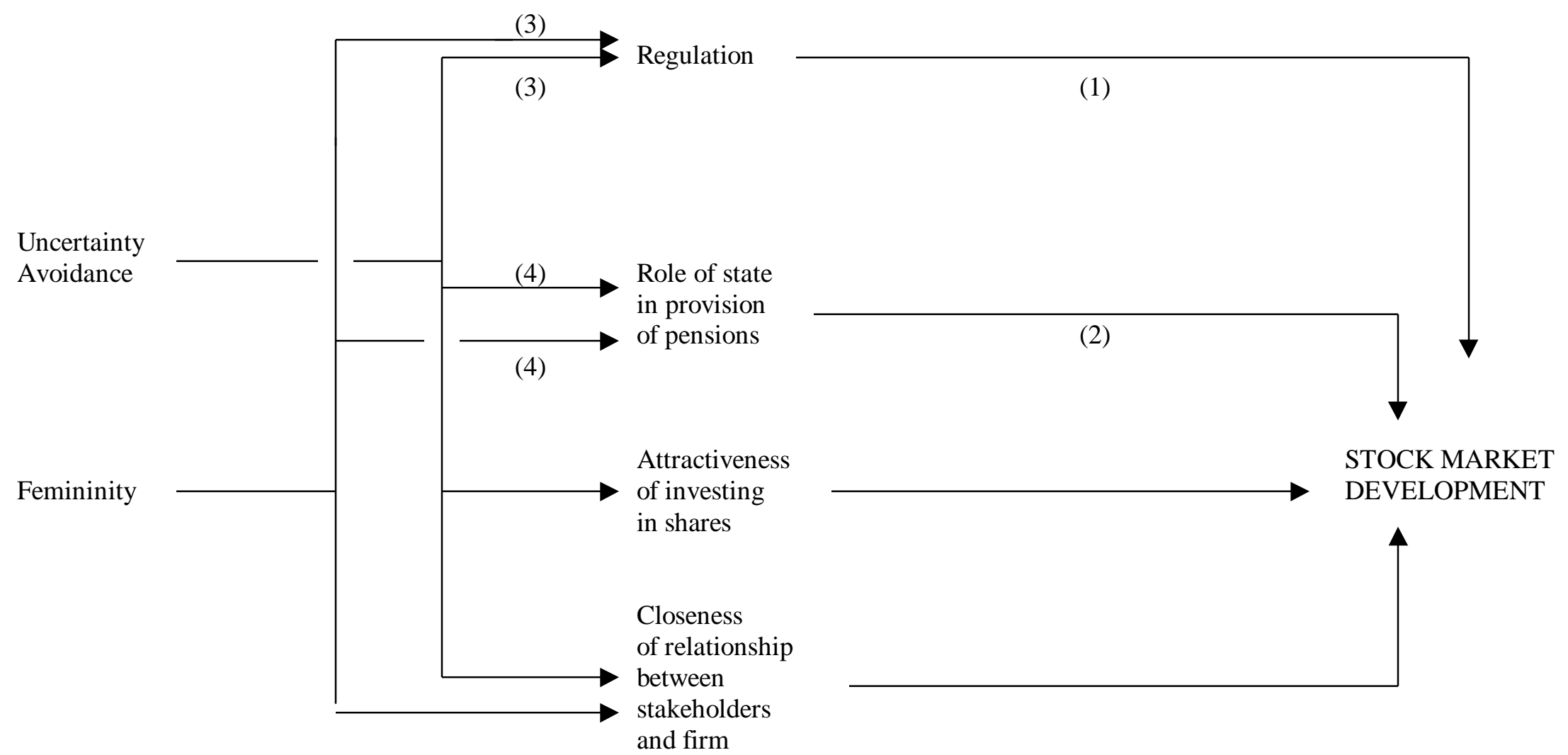

Note: The figures between brackets refer to the hypotheses as these are formulated in the text.

Hypothesis 5 covers all arrows between Uncertainty Avoidance and Femininity on the one hand and stock market development on the other. 